\title{
Fundamentals for cave back and in-ground monitoring using wireless technology
}

\author{
A Aguirre Elexon Mining, Australia \\ J Lloyd Elexon Mining, Australia
}

\begin{abstract}
The mining industry is pushing the boundaries in the application of cave mining with challenging ore bodies and ground conditions, production ramp-up, and higher throughput. With this, monitoring technologies need to progress to enable management of the associated geotechnical risks. Alongside recent advancements, wireless in-ground monitoring systems have emerged as a solution for monitoring ground stability and cave propagation in underground mining. Wireless in-ground monitoring can be used in a variety of monitoring scenarios where in-ground data collection is critical, such as cave back monitoring, mineral flow, caving-induced subsidence and cave interaction with open pits and tailing dams. This paper provides an introduction for the design, installation, and application of a wireless in-ground system, Geo4Sight, and discusses this system's operation, components, output data, interpretation, the determination of rock mass damage, and application thereof. This publication aims to provide an insight into the Geo4Sight system, and its relationship with ore flow monitoring (Cave Tracker System), highlighting the key aspects to consider for its correct application within the wider scheme of underground monitoring.
\end{abstract}

Keywords: monitoring, wireless, Geo4Sight, tilt, stability

\section{Introduction}

The ongoing development and expansion of mass mines throughout the world presents continuing safety and production challenges in the mining industry. Deeper mines, lower grades and complex geomechanical environments require innovative monitoring technologies to maintain and improve the quality of monitoring data. In many cases, due to the nature of mining methods, geotechnical monitoring systems are not just an option but a requirement.

Geotechnical monitoring is critical to managing mining operational risks and has a major impact on safety and economic performance. The geotechnical challenges in the mines are heightened by the historic 'black box' nature of the cave mining method. Traditionally, the caving method has not allowed the internal mining process (cave propagation and flow) to be effectively monitored. It is here where wireless monitoring systems stand out, allowing improvements to be made to existing measurements techniques as well as allowing new types of data to be measured. An example of this is the ability to obtain measured data from regions previously thought to be inaccessible, such as the seismogenic zone, yielded zone and cave zone (Board \& Pierce 2009).

This paper presents data from a wireless monitoring system, Geo4Sight, used to monitor in situ rock deformation in underground mines. The rock deformation is monitored by measuring changes to the 3D tilt angles of wireless Geo4Sight devices. A method is presented to classify in situ underground rock damage based on the monitored tilt data.

\section{$2 \quad$ In-ground monitoring}

Soil and subsoil monitoring are crucial to control and minimise the risks associated with movements and deformations of the rock mass. In-ground monitoring is a critical tool for effectively managing geotechnical risks and with this providing a method to implement preventative response measures. 
In-ground monitoring instruments can potentially detect critical changes in the ground, where most failures begin, long before topology monitoring methods indicate there is ground deformation on the surface.

In recent years, the installation of automated in situ monitoring systems has increased. However, installing wired systems to obtain data from sensors permanently installed in the ground is often a challenge.

The environment for in-ground monitoring is rough and rugged, especially for systems that rely on cables for power and data transmission. Mining equipment and moving ground damages cables, rendering expensive installations useless and ineffective. Mine operators cannot risk a situation where the information that geotechnical engineers rely upon is not available when it is most needed: when a failure needs to be avoided or mitigated. Redrilling and installing new monitoring systems after installed equipment has been damaged may be costly or impossible due to access restrictions.

Taking into account the aforementioned, below are some of the difficulties associated with in-ground monitoring:

- Data recovery reliant on physical data collection: some data loggers are not networked, requiring data to be obtained at the datalogger, which can be complicated because access to the monitoring sites can be limited (subsidence zones, etc.).

- Instruments typically only monitor one variable, e.g. inclinometer (tilt), vibrating wire piezometer (pore pressure). This results in higher hole expenses and more complicated designs.

- If the hole experiences a shearing event and the cable is damaged, this will result in data loss (Figure 1).

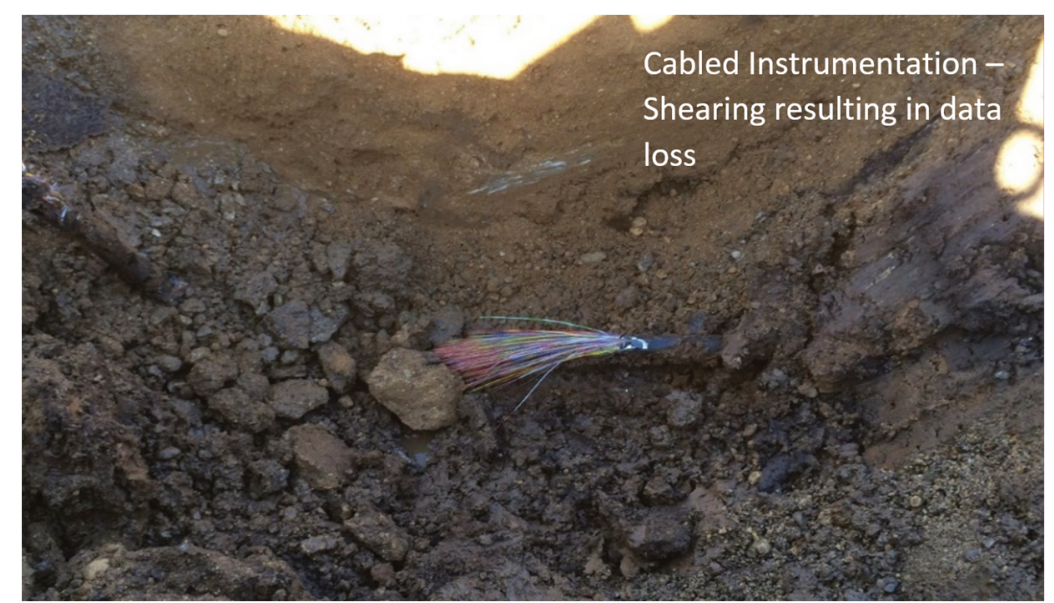

Figure 1 Sheared monitoring instrumentation cable

\section{$2.1 \quad$ Geo4Sight}

The Geo4Sight platform is a wireless system for subsurface monitoring in challenging geotechnical environments where the use of cabled monitoring systems is impossible, or where cables are at high risk of being damaged by moving ground.

Geo4Sight uses a wireless mesh network consisting of rugged battery-powered nodes to communicate sensor data from deep in the ground to surface. Geo4Sight nodes are installed into drill holes at regular intervals to enable data communication along the chain of the Geo4Sight nodes. The Geo4Sight platform was created to integrate a range of sensors (magnetometers, accelerometers, thermocouples, pore pressure sensors) into one package. The instruments are encapsulated in rugged, waterproof, and blast-proof cases that operate wirelessly and are battery-powered (Figure 2). The on-board accelerometers and magnetometers are used to determine device 3D tilt. An on-board radio transceiver is used to transmit measurement data to the surface in a daisy chain fashion. Ground deformation around the installation is determined by analysing the measured tilt and azimuth data. (Beingessner et al. 2020). 


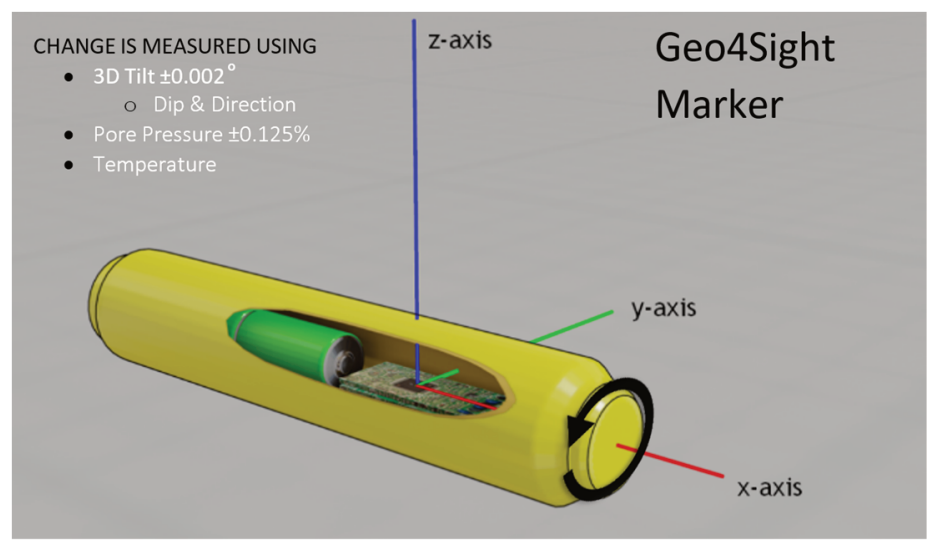

\section{Figure 2 Geo4Sight Markers}

The Geo4Sight can monitor movement, ground deformation and groundwater. The measurement of change is made by measuring $3 \mathrm{D}$ tilt with an accuracy of $\pm 0.002^{\circ}$, dip and direction, pore pressure with an accuracy of $\pm 0.125 \%$ and also temperature with an accuracy of $\pm 1 \%$.

\subsubsection{Operating method}

Geo4Sight utilises an ultra-low-power in-ground radio mesh network of Markers. The Markers have a radio communication range of $\sim 4.5 \mathrm{~m}$ through the ground, however, for redundancy and to allow for movement, they are installed much closer to each other (typically $2 \mathrm{~m}$ ). This redundancy enhances the capabilities of the system by providing additional data granularity.

Communication from the reader at the surface to any Marker in the hole is done by sending 'queries' down the chain, passing from one to the next until the destination Marker has been reached. When the query command is received, the destination Marker takes measurements and sends the data backup the chain to the reader to be recorded and transmitted to a database for analysis (Figure 3).

An antenna is required to communicate with the Markers in the hole. Typically, there is one antenna per hole and it is preferential that they are installed within the hole close to the first Marker. The antenna is cabled and plugs into the datalogger.

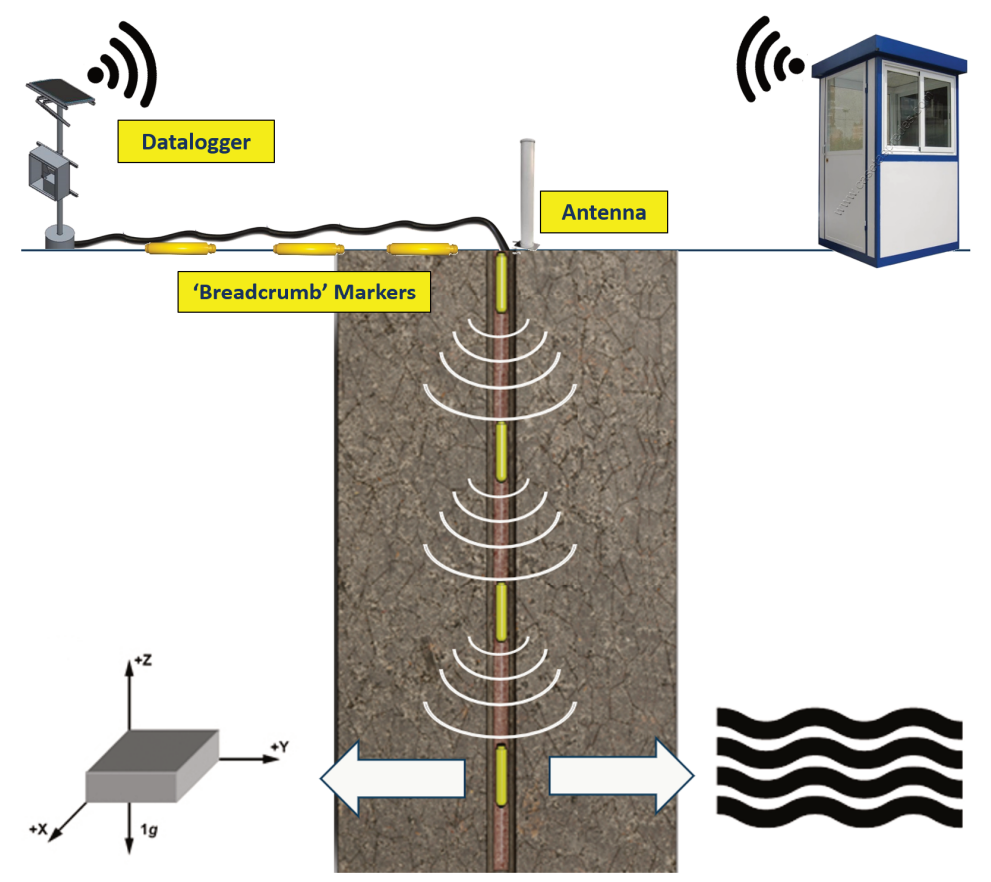

Figure 3 Geo4Sight operating principles 
The antenna cable is a fragility as it can be damaged from mining activities or expansion in the area, if loss of the antenna occurs, redundancy Markers can be placed from the datalogger to the hole collar to maintain communication. These 'breadcrumb' Markers can be bonded to the ground using grout. These also provide additional datapoints on a horizontal plane.

\subsubsection{Geo4Sight design}

When the Geo4Sight system is to be implemented at a site, several factors must be considered when designing the system installation layout:

- Rock quality: The quality of the rock mass is important when it comes to installing the sensors as poor rock quality can lead to clogging inside the hole or possible collapse. To avoid the difficulties associated with poor rock mass, the sensors can be installed through a drill string.

- Geology and lithology: In order to have a greater detail (resolution) of the rock mass profile, it is recommended to have a higher density of sensors in lithological layers where more information is required. Also, in areas where water is expected, install more sensors with pore pressure functionality. Instrumenting areas of high-grade deposits can provide management with early indications of caving. Conversely, areas of low grade can be avoided unless you are monitoring waste ingress. Geo4Sight has also been successfully deployed in a situation where fault monitoring was critical.

- Hole orientation and location: To extend the longevity and usefulness of the devices, it is advised the holes face the cave front, this is to minimise the hole being cut off mid-hole. Ideally, holes will be close to vertical, installed from the surface or a monitoring level. The verticality provides a clearer view of the cave back on the Z-axis. Ideally, the collar of the hole will be the last point to be consumed by mining activities. Drill rigs require certain spacing with regards to drive height and the dip/azimuth of the holes will need to take this into account.

- Spatial coverage: The holes should be evenly spaced apart to maximise spatial coverage for general cave monitoring. Ideally, the holes will not be collared from the same location. This unintentionally creates areas where there is a higher density of instruments. If there are access issues onsite, this may be the only option.

- Planning: To get accurate calibration data, all instruments should be installed prior to undercutting. Calibration data is important to assess the initial baseline rock mass measurements and condition before rock mass damage occurs due to mining.

- Critical infrastructure: Geo4Sight Markers can be installed at these structures with the toe of the hole facing the area that is likely to experience stress, e.g. Markers collared from the main incline facing the cave.

- Data logging positioning: The datalogger should be in a position where it can be accessed by personnel if required. The position is usually constrained to within $500 \mathrm{~m}$ due to the cable length of the antenna.

\subsubsection{Installation}

Marker holes are required to be fully grouted. This integrates the sensors directly with the rock mass, resulting in more accurate data. This also ensures the installed devices are appropriately constrained until the point of rock movement due to cave propagation.

Markers are nominally installed in $2 \mathrm{~m}$ intervals, in a continuous chain, from the collar location to the lowest point of interest within a borehole. The dimensions of the Markers (64 mm diameter and $300 \mathrm{~mm}$ long) allows them to be installed using standard $\mathrm{HQ}$ drilling diameters ( $96 \mathrm{~mm}$ diameter). 
Boreholes must be completely logged and georeferenced (collar location and gyroscopically surveyed) prior to installation. The Geo4Sight system requires this information to match each measurement Marker device with its depth and 3D position in the hole.

The monitoring systems must be able to function in the presence of extremely high hydrostatic pressures due to groundwater, water and drilling slurry from the drilling process and significant head pressures via the pumping of grout into the boreholes. Markers are designed for, and tested to, $20 \mathrm{MPa}$ (at room temperature). This is purely a calculation of passive head pressures and does not consider additional pumping pressure from the grouting process.

\subsubsection{Installation method}

Markers can be installed in both ascending and descending holes. This gives great flexibility for installing in sectors that have access constraints. A fibreglass rod is used to guide the Markers into their respective boreholes. The rod also maintains the required spacing (e.g. $2 \mathrm{~m}$ ) between devices (Figure 4).

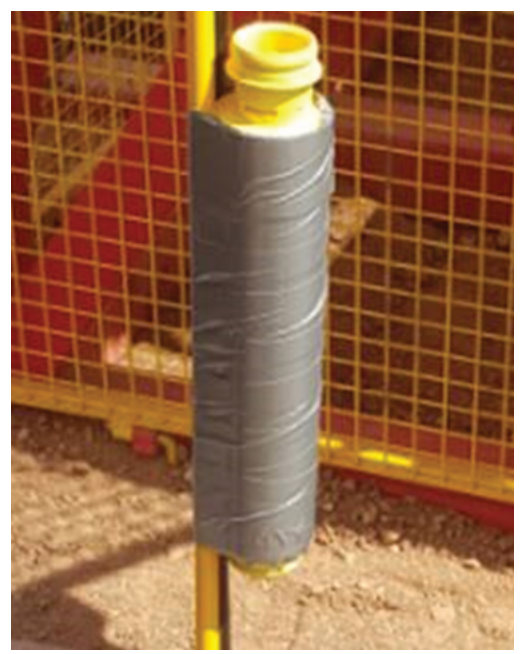

\section{Figure 4 Geo4Sight Marker attached to fibreglass rod}

Open holes without casing are preferable because interference with casing and the use of machinery is avoided, but this depends on ground quality. However, for up-holes, casing during installation is mandatory.

At the completion of installation, any remaining metal casing surrounding the Markers must be removed, as this affects each Markers magnetic field readings and ability of the Markers to communicate with their radios.

\subsubsection{Components}

The components of the Geo4Sight system are:

- Markers: Sensors capable of measuring tilt, 3D orientation of the tilt, pore pressure and temperature.

- Datalogging cabinet: Datalogger associated with the system where, depending on the project, requirements includes multiplexer, reader, battery, among other ancillary equipment, and can be connected to built-in solar panels to run 'off-the-grid', or powered by existing power infrastructure.

- G4S antenna: This is installed near the hole collar; it is the communication channel between the hole and the datalogger. 'Breadcrumb' Markers may be optionally run from the hole collar to a suitable antenna location.

- The GeoHive: Data 3D visualisation and analysis software. Surface topographies and mine designs can be imported to the GeoHive software, allowing data to be visualised in the context of the specific site. 


\section{Data analysis and application}

Once the Geo4Sight system is installed and commissioned data can be accessed from each of the readers. The data can be accessed via approved virtual machines or via the site's internal network.

\subsection{Data analysis}

The pore pressure, 3D tilt and temperature data may be analysed in three ways:

1. Raw exported time stamped data.

2. Graphed data.

3. Three-dimensional data visualised and automatically analysed by the GeoHive software (see following figures).

Data is typically acquired every day but can be acquired every week or every month, etc., depending on project requirements and lifetime constraints. For instance, Markers at the toe of a hole may be queried more frequently than those at a collar. To further extend a Markers life, they can be put into a sleep mode. For sleep mode to be enabled, a datalogger must be present to transmit the sleep commands.

Figure 5 shows data obtained from an uphole located in a crown pillar. The aim of the monitoring equipment in this area is to determine the interaction between an open pit and an advancing cave below.

The graph represents the cumulative change in tilt over time. Each coloured line is a particular sensor within the hole. Although there are a lot of series shown in this graph, there is a gradual tilt change trend for all Markers in the hole, until a large change was measured on 11 April 2020. This indicates complete fracturing of the rock mass. Visualising the data with the GeoHive software illustrates the rock mass activity in 3D (Figure 6). Each sphere represents a Marker and its corresponding change in tilt: the larger the sphere, the greater change in the tilt. In conjunction with the change in size of the sphere, the colour scale represents the change in tilt as well.

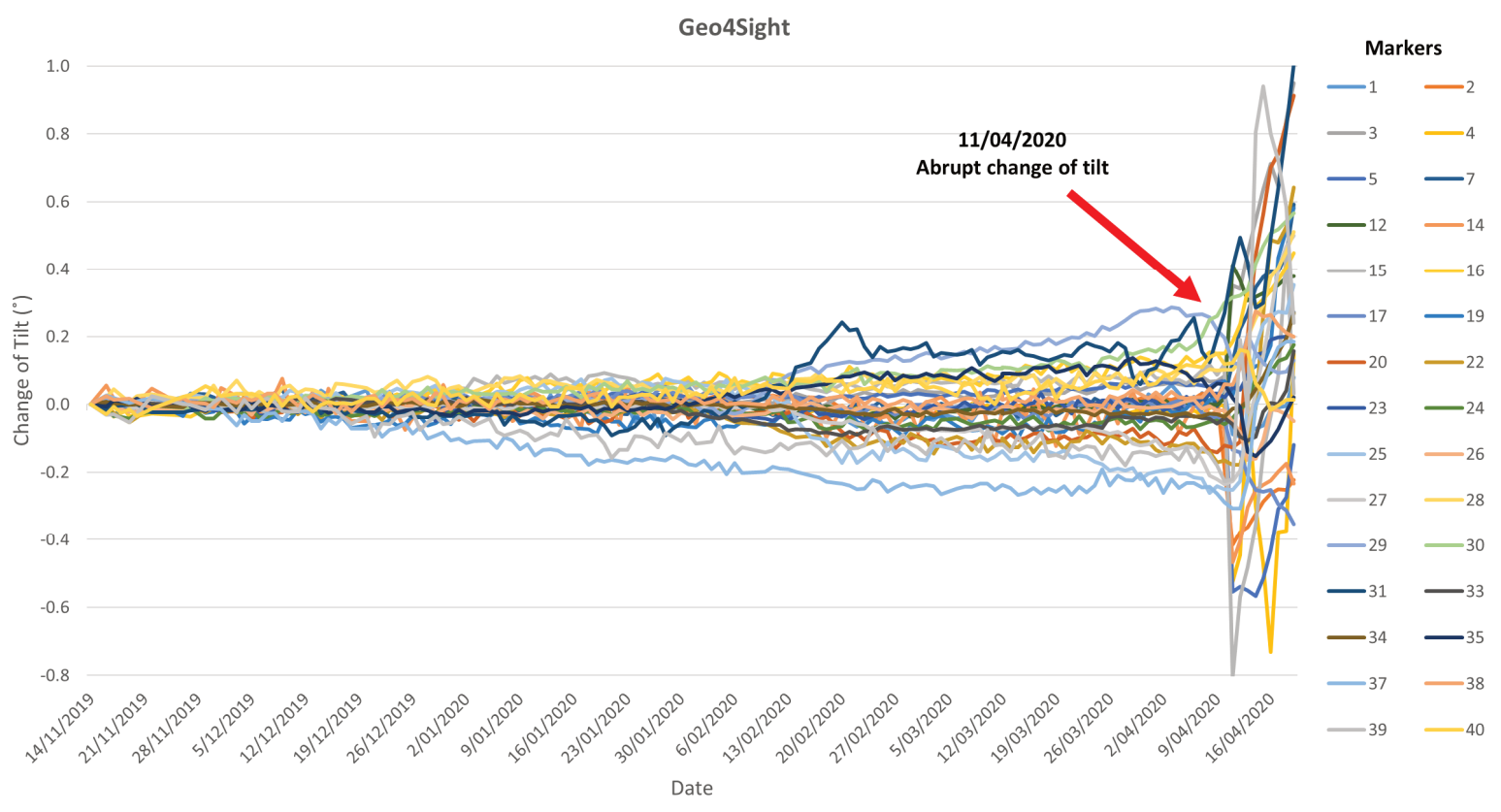

Figure 5 Tilt over time graph (crown pillar uphole) 


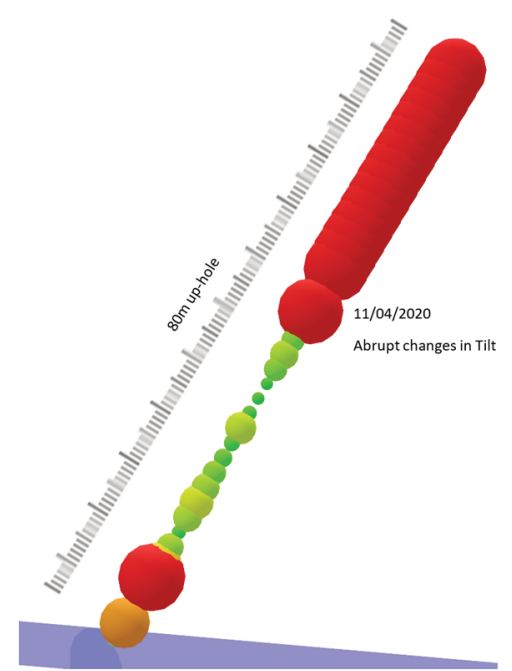

Figure 6 The GeoHive visualisation (crown pillar uphole)

As mentioned throughout the publication, one of the characteristics of the sensors is that they can measure the 3D orientation of the tilt with respect to the magnetic north pole, which gives us more information about what is actually happening within the rock mass.

For example, the crown pillar uphole (Figure 6) was drilled towards the south. In addition, the cave sequencing was advancing from a south-westerly direction. Figure 7 shows the top-down tilt orientation over time. Each grey circle on the graph represents the cumulative change in tilt.

The Markers were expected to be affected by the subsidence of the cave below, and the preferential orientation of the tilt is consistent with the advancing cave.

Ground deformation can be inferred from the data to the point of achieving complete fragmentation of the rock mass with a notable orientation, as indicated in the figure.

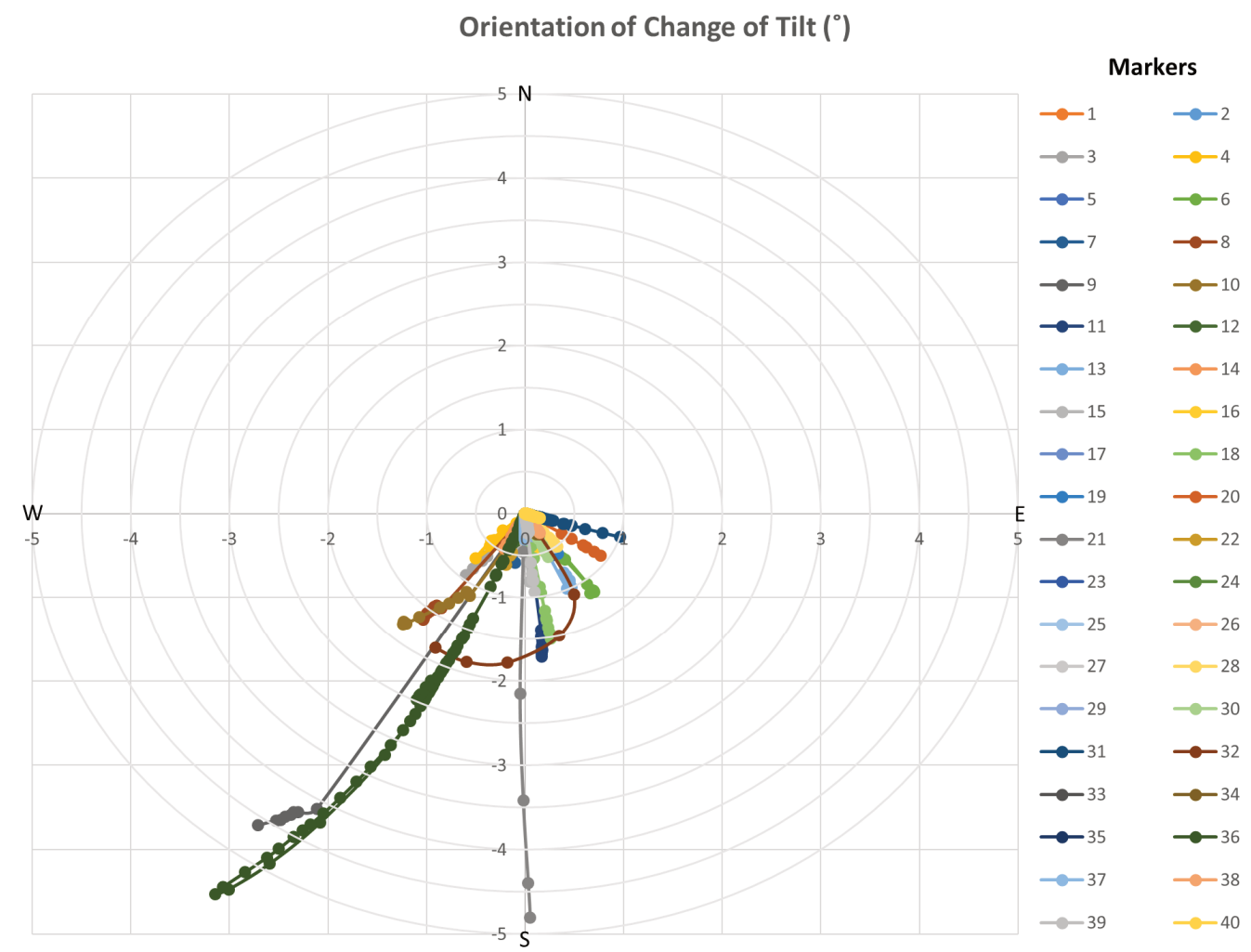

Figure 7 Graph of orientation and magnitude of change of cumulative tilt (crown pillar uphole) 
Figure 8 shows data obtained from a hole whose purpose was monitoring a fault. The fault was located to the west of the hole collar and the Markers intercepted the fault in a semi-horizontal inclination. The yellow plot with the largest positive inclination was Marker 28, whereas the blue plot with the most negative inclination was Marker 29. This data indicates the point at which the hole intercepts the fault, and the movement is associated with the continuous blocks of the fault.

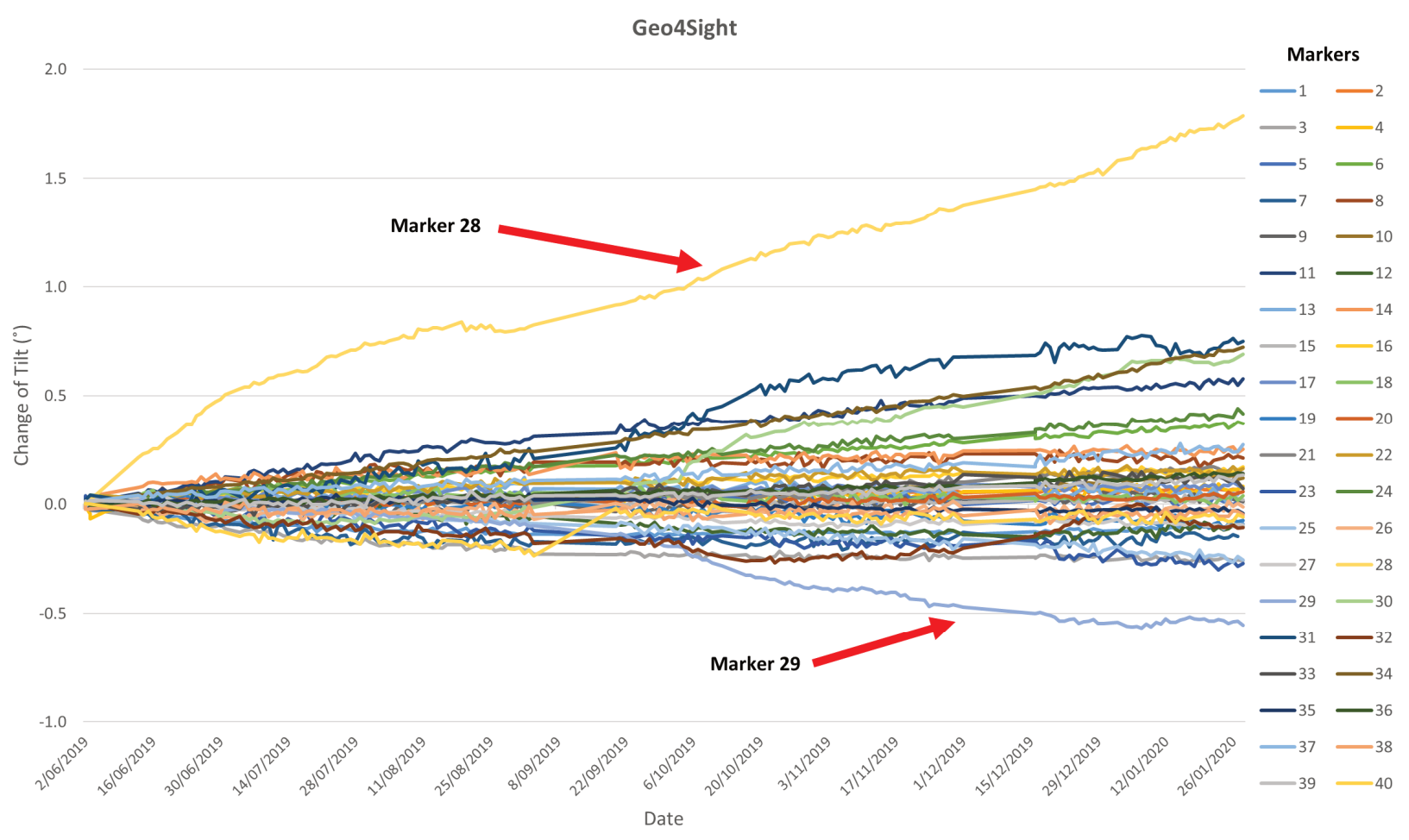

Figure 8 Tilt over time graph (hole through fault)

The GeoHive visualisation shows a high degree of tilt of a localised area (Figure 9 red spheres), we can assume this area is the fault. Similar to the previous crown pillar uphole we can view the orientation of the tilt (Figure 10), however, the tilt progresses in a linear fashion, this indicates the movement and deformation is not abrupt.

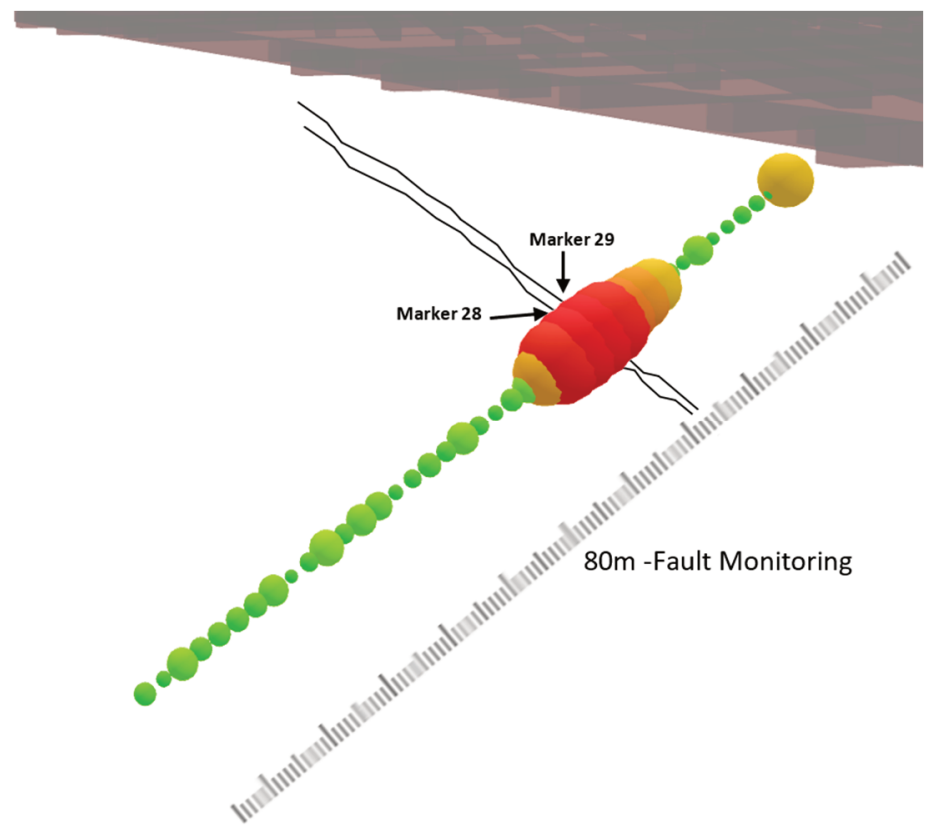

Figure 9 The GeoHive visualisation (hole through fault) 


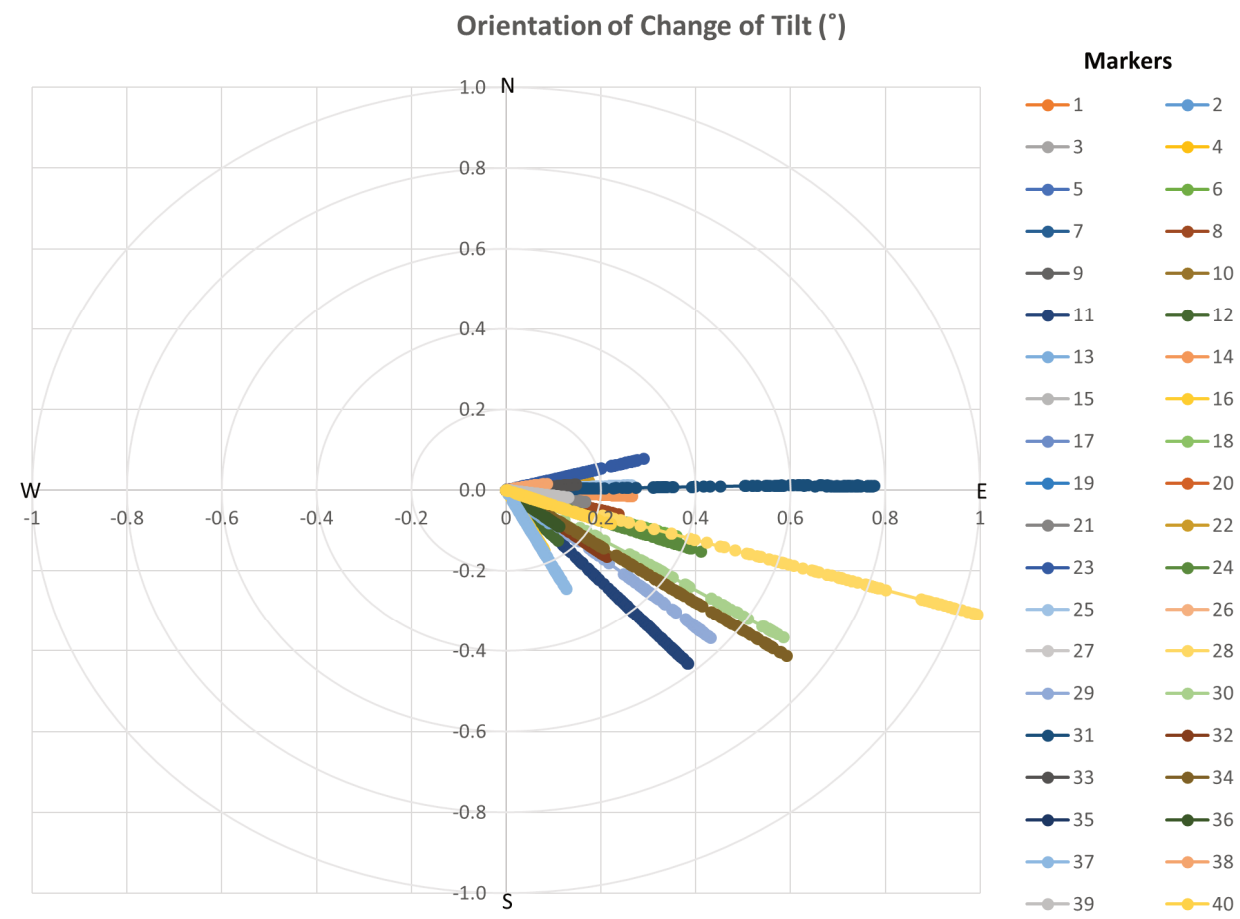

Figure 10 Graph of orientation and magnitude of change of cumulative tilt (hole through fault)

\subsection{Determining rock mass damage from tilt data}

Another area the data can be applied to is the determination of damage to the rock mass. From angular distortion, we can determine the horizontal strain and together with the following graph adapted from Darling (2011) (Figure 11), we can get insight into the rock mass damage.

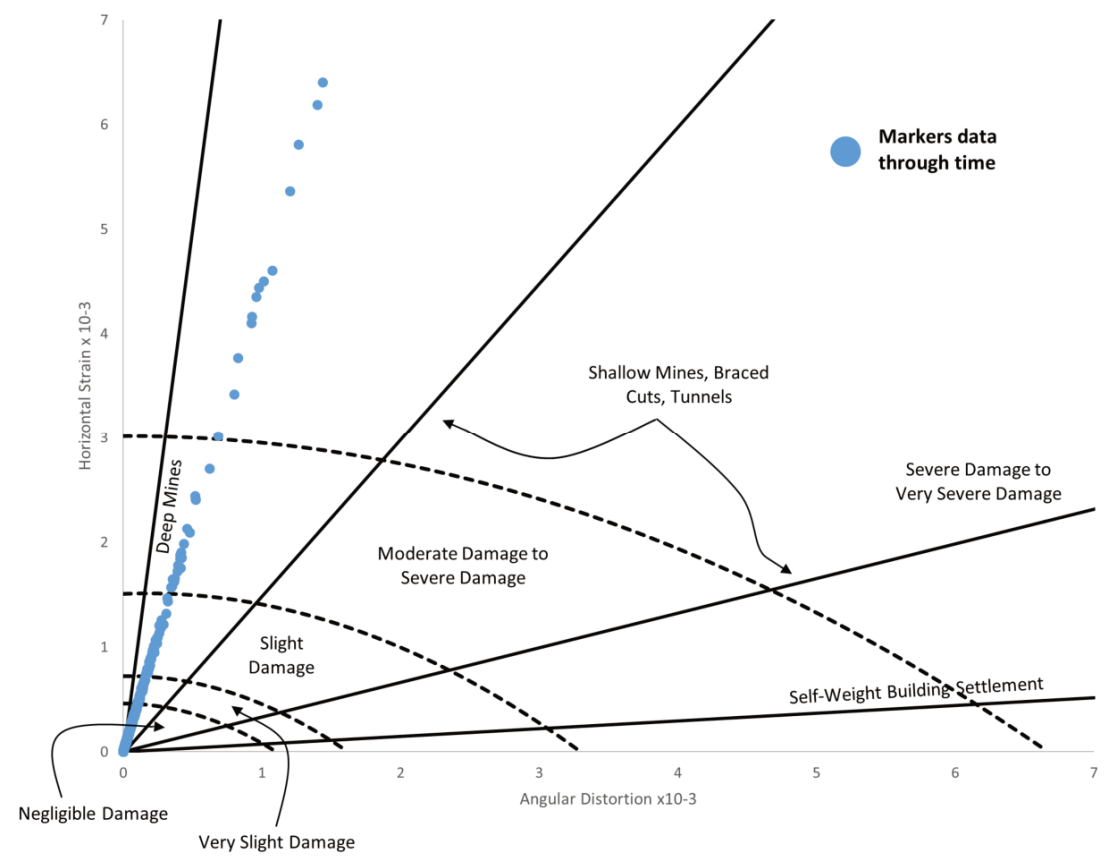

Figure 11 Building damage in terms of angular distortion and horizontal strain

The data in Figure 11 is from an uphole in the crown pillar, the same analysed previously. Preliminary results show the majority of the data collected is in the negligible damage zone, however, as data is obtained over time, specific Markers begin to show abrupt changes in tilt, which translates into greater horizontal strain, causing damage to the rock progressively. 
Although the damage areas of the rock mass are obtained from empirical data, it is possible to have an approximation of the damage that is occurring within the rock mass due to the tilt vector, since we know $3 \mathrm{D}$ orientation and magnitude. If the change in the tilt is cumulative (Figure 12), we can see how it increases for each Marker over time. This means that at some point, the cumulative change in horizontal strain will be of such a magnitude that it will cause damage to the rock mass and for that particular Marker data, it will go from being in a sector with less damage to one with more damage. Taking this concept into account over time, the damage that the rock will suffer can be foreseen.

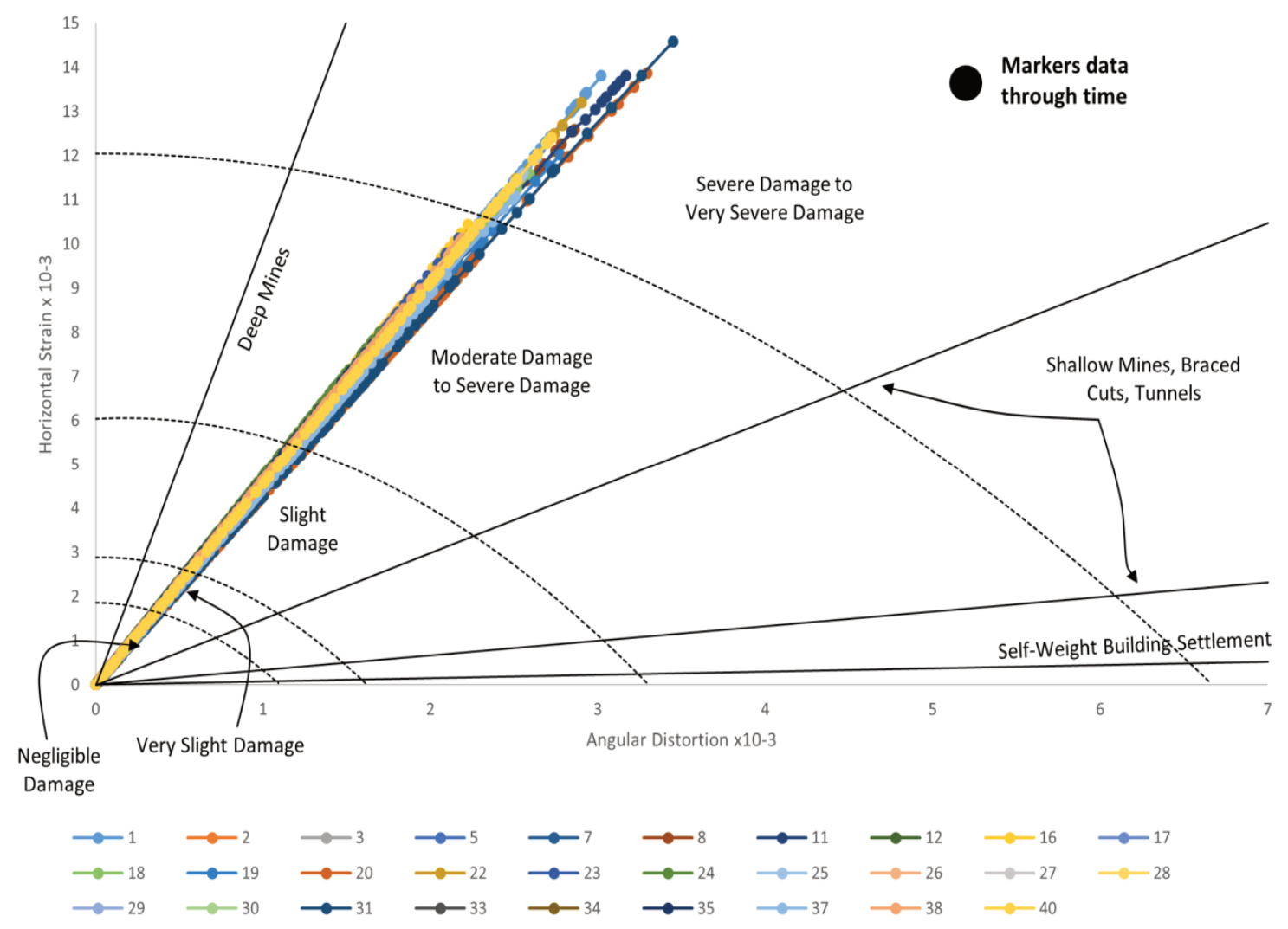

Figure 12 Damage in terms of angular distortion and horizontal strain for each Marker (cumulative)

\subsection{The GeoHive visualisation}

The GeoHive is a 3D visualiser in which you can import hole designs with tilt and pore pressure data. It is possible to import topographies and 3D models from .DXF files to show the data in the context of the mine. The change in tilt and communication of the Markers is represented through spheres: the larger the sphere, the greater the change in tilt or received signal strength indicator. The size and colour of the orb are linear in their progression: green implies that there are little to no changes in the measurements and as it progresses towards red, this indicates changes in the tilt (Figure 6). New visualisations are being developed that will allow you to graphically and more explicitly show the 3D orientation of the Marker. One of the new features is to see each Marker as a vector, where the arrow indicates the orientation and its length the magnitude of change in tilt, with a colour scale for the change in tilt (Figure 13). 


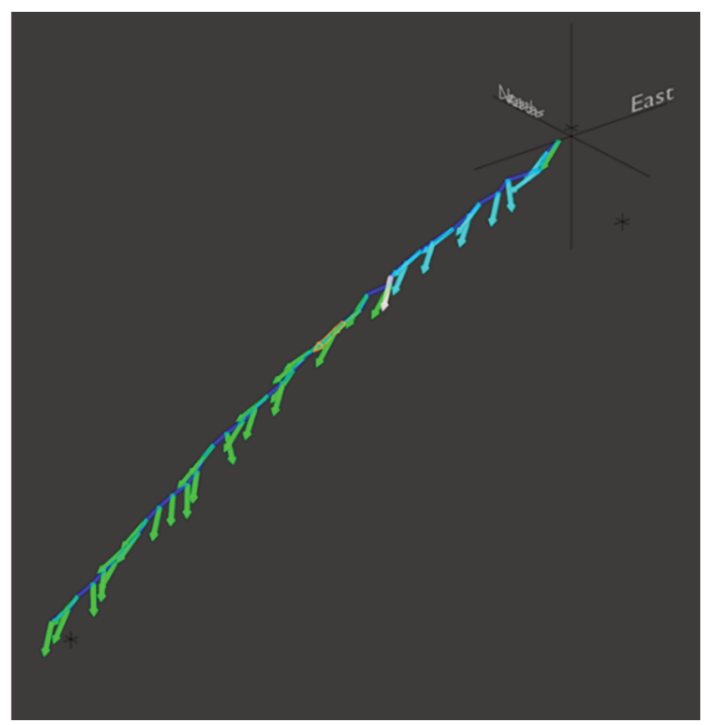

Figure 13 Hole profile tilt orientation

\section{$4 \quad$ Cave flow monitoring}

As mentioned, the Geo4Sight technology and protocol allow us to ascertain the cave propagation rate. As the Markers are consumed by the cave, i.e. we lose radio communication with them, we can infer the position of the cave back (Figure 14). Subtle tilt changes above the cave back portray zones such as the seismogenic zone and yield zone.

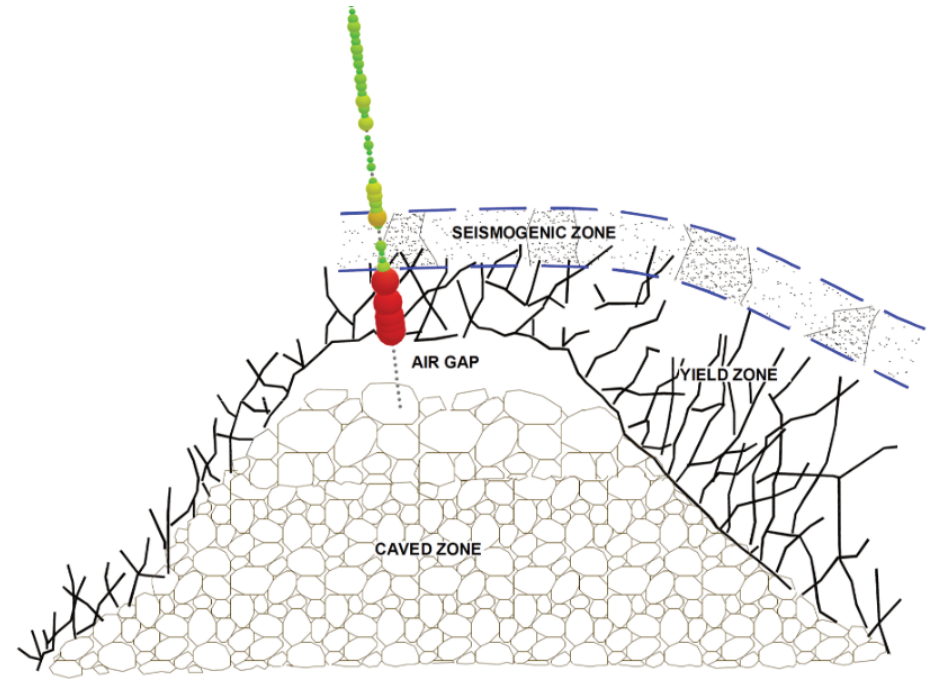

Figure 14 Cave back interpretation with Geo4Sight (after Board \& Pierce 2009)

For cave flow monitoring, the Cave Tracker System can be deployed. This is a monitoring system focussed on the mineral flow in real time (depending on the frequency of measurements that are made), and comprises Cave Tracker Beacons embedded into the orebody. Each Beacon contains a small, powerful, magnetic rotor that is programmed to spin at regular intervals. Cave Tracker Detectors placed in and around the mine sense the rotating magnetic fields from the underground Beacons using highly sensitive magnetometers.

The Detectors automatically record the 'spin events' from each Beacon and determine the distance to each Beacon's magnet based on the measured rotating magnetic field strength. This information is communicated to the Cave Tracker Management System (CTMS) over the mine's LAN.

The CTMS determines the underground 3D position of each Beacon by combining multiple Detector ranges and using a 3D triangulation technique called multilateration. 
By observing the 3D positions of the Beacons, the movement path of the ore in and around the mine can be tracked. Many important caving phenomena can be identified from this movement (or non-movement) information (e.g. cave propagation, rilling, dilution entry, etc.) (Figure 15).

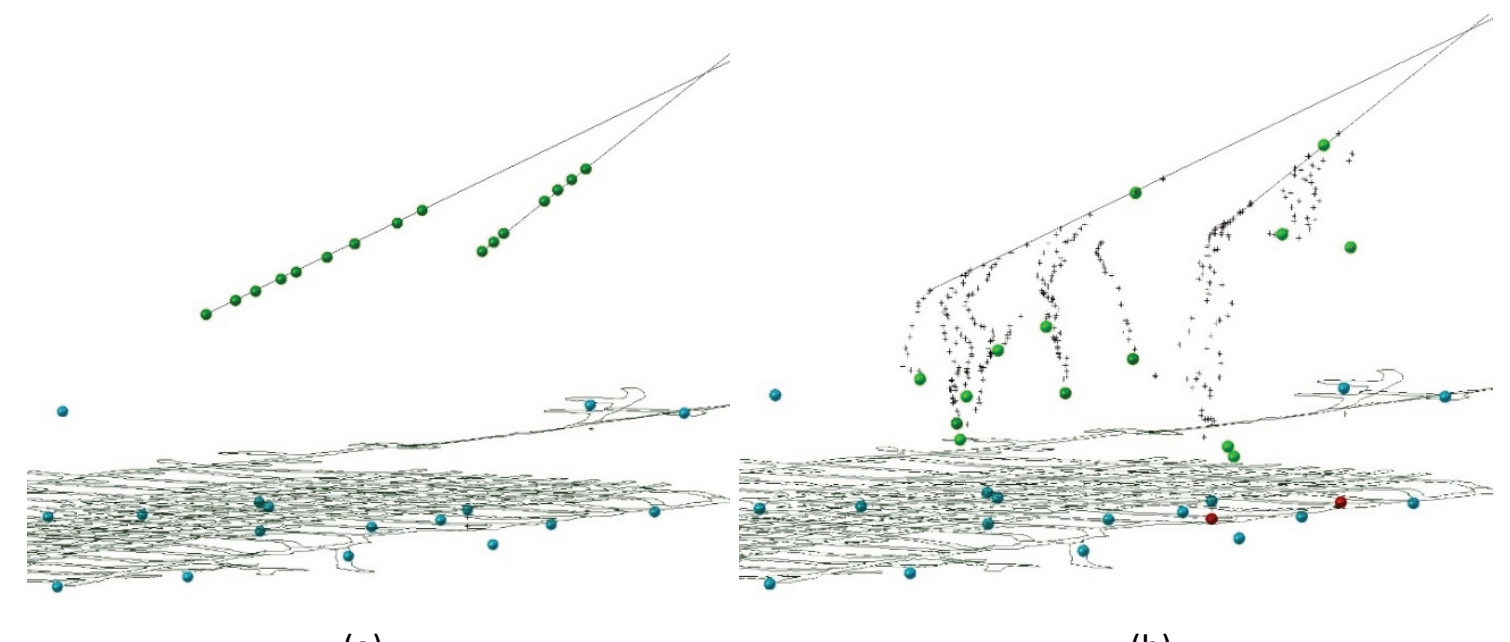

(a)

(b)

Figure 15 Cave tracker system Beacons. (a) Beacons (green spheres) in their installation positions; (b) Beacon movement

Visualising both of these complementary systems in the GeoHive can give the clearest view of the cave and its behaviour. One aspect is the high precision tilt measurement system, Geo4Sight, showing insight into the position of the cave back whilst also detecting possible preliminary movements of the rock mass and the other aspect is a monitoring system for the flow of the mineral in the caved zone, as it progresses to the extraction level. If Beacons are moving in the muck pile and Geo4Sight is not reporting change in competent rock, you can infer that an airgap is developing. With this, a complete review can be performed, which may lead to a change in the caving strategy.

\section{Conclusion}

Geo4Sight Markers have been installed into tens of thousands of metres of drill holes spanning over seven to eight years. This paper contains learnings from recent successful projects. The field of in-ground monitoring in underground mining is vast and ever-changing. Only in recent times has advanced monitoring been available to remove some of the presumptions typically associated with cave-shape analysis. The aim for the future is to separate these assumptions entirely and to 'close the loop' so that underground mines can operate with a high degree of autonomy, increasing efficiency, throughput, and most importantly, safety.

\section{Acknowledgement}

The authors acknowledge their colleagues at Elexon Mining for providing the opportunity to publish this paper, as well as providing support behind the scenes during its completion.

\section{References}

Beingessner, T, Yost, R, Steffen, S, Whiteman, D, Thomas, AM, Royle, M \& Widzykcapehart, E 2020, 'Post-shearing data collection with enhanced network smart Markers', in PM Dight (ed.), Proceedings of the 2020 International Symposium on Slope Stability in Open Pit Mining and Civil Engineering, Perth, pp. 307-318, https://doi.org/10.36487/ACG_repo/2025_16

Board, M \& Pierce, M 2009, 'A review of recent experience in modelling of caving', International Workshop on Numerical Modelling for Underground Mine Excavation Design, in conjunction with the 43rd US Rock Mechanics Symposium.

Darling, P 2011, 'Mine subsidence', in JP Harrison (ed.), SME Mining Engineering Handbook, 3rd edn, Society for Mining, Metallurgy, and Exploration, Inc., Englewood. 